\title{
Determinant factors of home delivery among women in Northern Ethiopia: a case control study
}

\author{
Resom Tsegay ${ }^{1 *}$, Alemseged Aregay ${ }^{2}$, Kalayu Kidanu $^{3}$, Mussie Alemayehu ${ }^{2}$ and Gebrezigabiher Yohannes ${ }^{4}$
}

\begin{abstract}
Background: Maternal mortality remains a major challenge to health systems worldwide. Although most pregnancies and births are uneventful, approximately $15 \%$ of all pregnant women develop potentially life-threatening complications. Home delivery in this context can be acutely threatening, particularly in developing countries where emergency care and transportation are less available. This study identifies factors associated with home delivery in Tanqua-Abergele District, Tigray, northern Ethiopia.

Methods: Unmatched case-control study was conducted in April 2014 in Tanqua-Abergele, Tigray, northern Ethiopia. Simple random sampling was employed to select study participants. Data were analyzed using SPSS 20. Multi variable logistic regression analysis was used to identify independent predictors of home delivery.

Results: A total of 275 women (92 cases and 183 controls) participated in the study, giving a response rate of $96.5 \%$. Not owning a radio or television (AOR: 7.2, 95\% Cl: 2.7-19.3), not pursuing ANC visits at all (AOR: 10.4, 95\% Cl: 2.9-37.1) orhaving1-3 ANC visits only (AOR: 4.75, 95\% Cl: 1.69-13.31),poor knowledge of obstetric complications (AOR: 8.7, 95\% Cl: 2.3-32.9) and walking time greater than two hours to the nearest health center (AOR: 5.1, 95\% Cl: 1.2-20.7) were strong predictors of home delivery.

Conclusion: Unable to meet the minimum requirement WHO of ANC service had a potential to give birth at home. Investing in infrastructure will contribute to improving maternal health. Having a different source of media (radio or television) could have a role in increasing the institutional delivery. Policy makers and other concerned bodies should give due attention to the fulfillment of infrastructure and educate women on the importance of institutional delivery.
\end{abstract}

Keywords: Home delivery, Maternal mortality, Tanqua-Abergele, Tigray, Ethiopia

\section{Background}

Maternal mortality remains a major challenge to health systems worldwide. Globally, there were 287,000 maternal deaths in 2010. Of the 287,000 maternal deaths worldwide, $85 \%$ occurred in Sub-Saharan Africa (SSA) and Southern Asia [1]. The maternal mortality rate (MMR) in Ethiopia is high (676/100,000 live births), despite the recognition of maternal mortality as a major public health issue [2]. Skilled attendants assist in more than $99 \%$ of births in developed countries compared with $62 \%$ in developing countries [3]. In Ethiopia, the situation is even

\footnotetext{
* Correspondence: resomtsegay@gmail.com

${ }^{1}$ Areaya Kahsu Health Science college, Department of Midwifery, Axum,

Tigray, Ethiopia

Full list of author information is available at the end of the article
}

worse - nine in ten women give birth at home [2]. Based on Tigray Regional Health Bureau's annual profile 2013, home deliveries in the region and Tanqua-Abergele District were $43.4 \%$ and $62.8 \%$, respectively [4]. Home deliveries are bound to be un-hygienic, unsupervised and, when intervention is required, it is usually late [3].

One factor associated with maternal and neonatal mortality is home delivery. These deliveries are largely unplanned, accidental and supported by unskilled health professionals, if at all. The home environment as a place of delivery in developing countries is shown to unsafe and may have adverse neonatal and maternal outcomes [5]. Interestingly, a large proportion of these maternal deaths could be prevented through timely and appropriate interventions. The presence of skilled delivery service 
utilization at each birth can significantly reduce maternal morbidity and mortality [6, 7]. Home delivery is associated with young maternal age, low educational attainment, rural residence, low socioeconomic status, high birth order, the absence of ANC services, distance to health facilities and complications during delivery [8-10].In contrast, having good knowledge of obstetric complications can enhance institutional delivery [11]. Still, many studies show that mother's awareness of danger signs of pregnancy is poor and affected by educational status, occupation-[12], and residential area [13].

During the past fifteen years, the Federal Ministry of Health (FMoH) has built an impressive framework for improving health for all, including maternal and neonatal health. There are strategies for free maternal and child health services. Activities include deploying Health Officers with MSc training in Integrated Emergency Obstetrics and Surgery (IEOS), improving the availability of safe blood and pharmaceutical supplies and a strong referral system. In addition to these activities, Tigray region has undertaken different activities to avert home delivery [4], including establishing a new structure at the community level below Health Extension Workers (HEW). The "Women Development Army" enables women to talk about pregnancy and delivery, making health facilities more friendly to the community, creating forums for pregnant women, the opening of maternity waiting home at health facilities, increasing the number ambulance services and availing of traditional ambulances for early referrals in case of emergencies [4]. Despite these efforts, the rate of home delivery in Tanqua-Abergele District is still high.

\section{Methods}

The study was conducted in Tanqua-Abergele District in northern Ethiopia from April 1 to 30, 2014. TanquaAbergele has five health centers and 16 health posts [4]. A community-based unmatched case-control study was used to enroll women who gave birth in the 6 months preceding data collection. Among this group, women who gave birth at home were considered as cases and those who gave birth at health institutions were controls. The total number of pregnant women was 3,360 and there were 331 home and 931 institutional deliveries from JulyDecember 2013(report from Tanqua-AbergeleWoreda Health Office, December 2013).

The following assumptions were made in calculating sample size: $95 \%$ confidence level and $80 \%$ power. General knowledge about obstetric complications was used as the exposure variable. The proportion of controls with good knowledge was $80 \%$ as well as $62.9 \%$ of cases [11]. Sample size was calculated using Open Epi version 2.3 with a case to control the ratio of $1: 2$. After adding $10 \%$ non-response, total sample size was 285 , including
95 for cases and 190 for controls. Simple random sampling was used to select study participants using the master family index as the sampling frame. TanquaAbergele has a total of 20 kebeles, the lowest

Table 1 Socio-demographic characteristics of study participants in Tanqua-Abergele District, Tigray, north Ethiopia, 2014

\begin{tabular}{|c|c|c|c|}
\hline Variables & $\begin{array}{l}\text { Cases } \\
\text { No (\%) }\end{array}$ & $\begin{array}{l}\text { Controls } \\
\text { No }(\%)\end{array}$ & $\begin{array}{l}\text { Chi-square, } \\
\mathrm{df}, p \text {-value }\end{array}$ \\
\hline \multicolumn{4}{|l|}{ Residence of respondents } \\
\hline Rural & $90(97.8)$ & $138(75.4)$ & $x^{2}=21.71, d f=1$ \\
\hline Semi urban & $2(2.2)$ & $45(24.6)$ & $P$-value $=0.000$ \\
\hline \multicolumn{4}{|l|}{ Age of respondents } \\
\hline $15-19$ & $3(3.3)$ & $25(13.7)$ & $x 2=15.361$ \\
\hline $20-24$ & $21(22.8)$ & $46(25.1)$ & $\mathrm{df}=4$ \\
\hline $25-29$ & $24(26.1)$ & $58(31.7)$ & $p$-value $=0.004$ \\
\hline $30-34$ & $26(28.3)$ & $24(13.1)$ & \\
\hline $35-39$ & 18(19.6) & $30(16.4)$ & \\
\hline \multicolumn{4}{|l|}{ monthly income (\$) } \\
\hline$<50$ & $85(92.2)$ & 136(74.3) & $x 2=12.69$ \\
\hline $50-99.5$ & $4(4.3)$ & $25(13.7)$ & $d f=2$ \\
\hline$>=100$ & $3(3.3)$ & $22(12.0)$ & $p$-value $=0.002$ \\
\hline \multicolumn{4}{|l|}{ Marital status } \\
\hline Married & $88(95.7)$ & $168(91.8)$ & $x^{2}=1.41, d f=1$ \\
\hline Others $^{\mathrm{a}}$ & $4(4.3)$ & $15(8.2)$ & $p$-value $=0.235$ \\
\hline \multicolumn{4}{|l|}{ Maternal educational level } \\
\hline Illiterate & $68(73.9)$ & $96(52.5)$ & $x 2=14.57$ \\
\hline Primary (1-8) & 19(20.7) & $50(27.3)$ & $d f=2$ \\
\hline Secondary and above & $5(5.4)$ & $37(20.2)$ & $p$-value $=0.001$ \\
\hline \multicolumn{4}{|l|}{ Husband educational level } \\
\hline Illiterate & $49(55.7)$ & $62(36.9)$ & $x 2=8.91$ \\
\hline Primary (1-8) & $33(37.5)$ & $83(49.4)$ & $d f=2$ \\
\hline Secondary and above & $6(6.8)$ & 23(13.7) & $p$-value $=0.012$ \\
\hline \multicolumn{4}{|l|}{ Maternal occupation } \\
\hline Housewife & $40(43.5)$ & $89(48.6)$ & $x^{2}=2.772$ \\
\hline Farmer & $44(47.8)$ & 70 (38.3) & $d f=3$ \\
\hline Employed & $6(6.5)$ & $17(9.3)$ & $p$-value $=0.428$ \\
\hline Student & $2(2.2)$ & $7(3.8)$ & \\
\hline \multicolumn{4}{|l|}{ Ethnicity } \\
\hline Tigre & 90 (97.8) & $177(96.7)$ & $x^{2}=0.265, d f=1$ \\
\hline Amhara & $2(2.2)$ & $6(3.3)$ & $p$-value $=0.607$ \\
\hline \multicolumn{4}{|l|}{ Religion of respondents } \\
\hline Orthodox & $92(100)$ & $182(99.5)$ & $x^{2}=.505, \mathrm{df}=1$ \\
\hline Muslim & $0(0.0)$ & $1(0.5)$ & $p$-value $=0.478$ \\
\hline \multicolumn{4}{|l|}{ Have a radio or TV } \\
\hline No & $69(75)$ & $83(45.4)$ & $x^{2}=21.76, d f=1$ \\
\hline Yes & $23(25)$ & $100(54.6)$ & $p$-value $=0.000$ \\
\hline
\end{tabular}

${ }^{\mathrm{a}}$ Single, widowed and divorced 
Table 2 Reproductive and obstetric related characteristics of study participants in Tanqua-Abergele District, Tigray, north Ethiopia, 2014

\begin{tabular}{|c|c|c|c|}
\hline Variables & $\begin{array}{l}\text { Cases } \\
\text { No }(\%)\end{array}$ & $\begin{array}{l}\text { Controls } \\
\text { No }(\%)\end{array}$ & $\begin{array}{l}\text { Chi-square, } \\
\text { df, } p \text {-value }\end{array}$ \\
\hline \multicolumn{4}{|l|}{ Parity } \\
\hline Primipara & $7(7.6)$ & $47(25.7)$ & $x^{2}=12.674, d f=1$ \\
\hline Multiparous & 85(92.4) & 136(74.3) & $P$-value $=0.000$ \\
\hline \multicolumn{4}{|l|}{ Ever had abortion } \\
\hline No & 79(85.9) & 158(86.3) & $x 2=0.011, d f=1$ \\
\hline Yes & 13(14.1) & 25(13.7) & $P$-value $=0.915$ \\
\hline \multicolumn{4}{|l|}{ Number of abortion } \\
\hline 1 & 10(76.9) & $17(68.0)$ & $x 2=0.331, d f=1$ \\
\hline$>=2$ & $3(23.1)$ & $8(32.0)$ & $P$-value $=0.565$ \\
\hline \multicolumn{4}{|l|}{ Ever had still birth } \\
\hline No & $76(82.6)$ & 156(85.2) & $x 2=0.323, d f=1$ \\
\hline Yes & $16(17.4)$ & $27(14.8)$ & $P$-value $=0.570$ \\
\hline \multicolumn{4}{|l|}{ Number of still birth } \\
\hline 1 & $10(62.5)$ & $21(77.8)$ & $x^{2}=1.166, d f=1$ \\
\hline$>=2$ & $6(37.5)$ & $6(22.2)$ & $P$-value $=0.280$ \\
\hline \multicolumn{4}{|l|}{$\begin{array}{l}\text { Last pregnancy } \\
\text { planned }\end{array}$} \\
\hline No & $20(21.7)$ & $29(15.8)$ & $x 2=1.411, d f=1$ \\
\hline Yes & $72(78.3)$ & 154(84.2) & $P$-value $=0.228$ \\
\hline \multicolumn{4}{|l|}{ Number of ANC visit } \\
\hline no visit & 33(35.9) & $13(7.1)$ & $x^{2}=62.594$ \\
\hline 1-3visit & $45(48.9)$ & $59(32.2)$ & $\mathrm{df}=2$ \\
\hline four and above & $14(15.2)$ & $111(60.7)$ & $p$-value $=0.000$ \\
\hline \multicolumn{4}{|c|}{ Timing of ANC follow-up } \\
\hline$<12$ weeks & 20(33.9) & $71(41.8)$ & $x 2=3.402$ \\
\hline 12-24weeks & $32(54.2)$ & $90(52.9)$ & $d f=2$ \\
\hline$>24$ weeks & $7(11.9)$ & $9(5.3)$ & $p$-value $=0.183$ \\
\hline \multicolumn{4}{|l|}{$\begin{array}{l}\text { Ever had obstetric } \\
\text { complication }\end{array}$} \\
\hline No & $60(65.2)$ & 115(62.8) & $x 2=0.149, d f=1$ \\
\hline Yes & $32(34.8)$ & $68(37.2)$ & $P$-value $=0.699$ \\
\hline \multicolumn{4}{|l|}{$\begin{array}{l}\text { Decision maker for } \\
\text { place of birth }\end{array}$} \\
\hline Non autonomous & $28(30.5)$ & $45(24.6)$ & $x 2=1.073, d f=1$ \\
\hline Autonomous & $64(69.5)$ & 138(75.4) & $P$-value $=0.300$ \\
\hline \multicolumn{4}{|l|}{$\begin{array}{l}\text { knowledge on } \\
\text { danger signs of } \\
\text { pregnancy }\end{array}$} \\
\hline Poor knowledge & $67(72.8)$ & $75(41)$ & $x^{2}=24.857, d f=1$ \\
\hline Good knowledge & $25(27.2)$ & 108(59) & $P$-value $=0.000$ \\
\hline
\end{tabular}

Table 2 Reproductive and obstetric related characteristics of study participants in Tanqua-Abergele District, Tigray, north Ethiopia, 2014 (Continued)

\begin{tabular}{llll}
\hline $\begin{array}{l}\text { General knowledge } \\
\text { of obstetric } \\
\text { complication }\end{array}$ & & & \\
$\quad$ Poor & $82(89.1)$ & $99(54.1)$ & $\times 2=33.475$ \\
Fair & $5(5.4)$ & $36(19.7)$ & $\mathrm{df}=2$ \\
Good & $5(5.4)$ & $48(26.2)$ & $p$-value $=0.000$ \\
\hline
\end{tabular}

administrative unit in Ethiopia, and all kebeles were included in the study. Sample was allocated proportionally to population across all 20 kebeles based on the number of women who gave birth at home and health institution in the six months preceding the survey.

A semi-structured, pre-tested questionnaire adapted from several studies $[2,11,14,15]$ and covering sociodemographic, health care and obstetric related factors were used. Ten data collectors who had completed Grade 10 and two (2) diploma nurse supervisors were trained for two days. The questionnaire was initially prepared in English and translated to Tigrigna. It was then checked for consistency by back-translation to English by language experts. Pretest was done two weeks before the survey in Deguaa-TembenWoreda, on 14 (5\%) of the sample (5cases and 9controls). Based on the pretest, a questionnaire was corrected to ensure clarity, wording, and logic sequence and skip patterns.

\section{Measurement}

Knowledge about danger signs during pregnancy was measured by comparing mean score responses to eight danger signs. Those with scores at or below the mean were classified as having "poor knowledge" while those with scores above the mean were categorized as having "good knowledge" [11].

General knowledge of obstetric complications was measured by calculating composite scores to seven obstetric complications, which were then categorized into" good", "fair" and "bad "levels of knowledge. Respondents with "good knowledge" included that scoring 75\% and above; "moderate knowledge" included those with scores between 50 to $74 \%$ and; "poor knowledge" characterized those that scored less than $50 \%$ [11].

\section{Data processing and analysis}

Data entry, cleaning, and analysis were done using SPSS version 20. Data was summarized and descriptive statistics were computed for all variables according to type. Frequency, mean and standard deviation were obtained for continuous variables while categorical variables were assessed using frequencies. A binary analysis was used to 


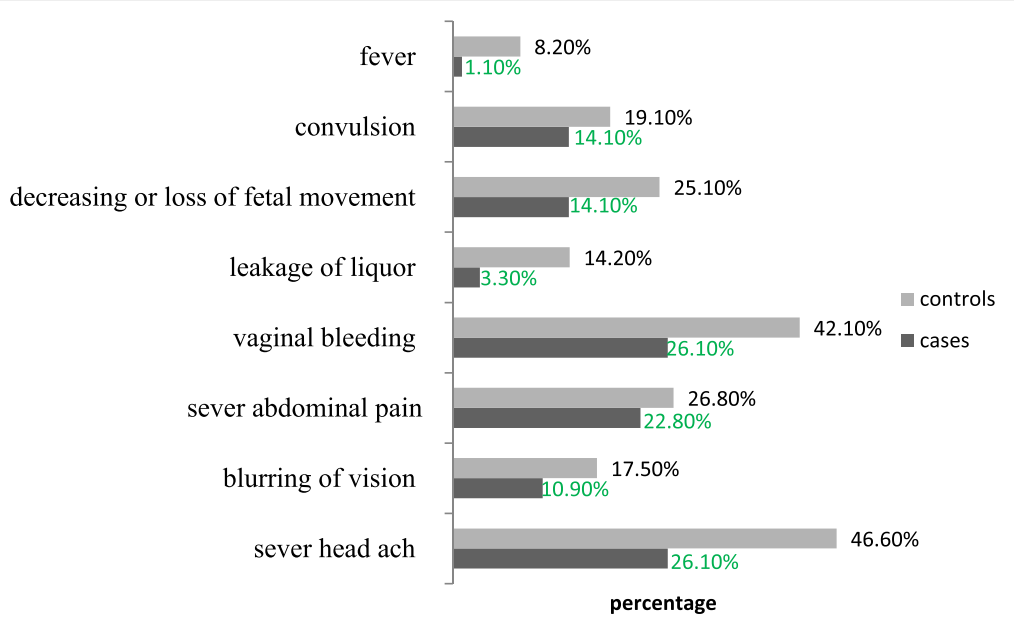

Fig. 1 Percentage of women's knowledge on danger sign during pregnancy in Tanqua-Abergele district, Central zone, Tigray, Ethiopia, 2014

describe the association between independent and dependent variables. A multivariable logistic regression analysis identified determinants of home delivery at $95 \%$ $\mathrm{CI}$ and $P$-value $<0.05$. The final model was fitted using the Hosmer-Lemeshow Goodness of Fit test. Multicollinearity was checked along with all the analysis.

\section{Results}

\section{Socio-demographic characteristics of the study participants}

A total of 275 respondents (92 cases and 183 controls), participated in the study, giving a response rate of $96.5 \%$. Mean age of cases and controls was $28.6(\mathrm{SD} \pm 5.5)$ and $26.6(\mathrm{SD} \pm 5.9)$ years, respectively, and ranging from 16 to 39 years. Majority of cases were illiterate $(68,73.9 \%)$ cases as well as 96 (52.5\%) controls. Median monthly family income for cases and controls was $\$ 22.50(\mathrm{IQR} \pm \$ 22.50)$ and
$\$ 37.50(\mathrm{IQR} \pm 400)$, respectively. Almost all respondents were Orthodox Christian and married (256, 93.1\%). Fortyfour $(47.8 \%)$ cases and $89(48.6 \%)$ controls were farmers and housewives by occupation, respectively. Approximately half of cases' husbands were illiterate. Eighty-three (49.4\%) controls' husbands' had attended grade one to eight, respectively. Around $75 \%$ of cases and $45.4 \%$ of controls did not have a radio or television (Table 1).

\section{Reproductive and obstetric related characteristics of study participants}

The majority of cases $(85,92.4 \%)$ and $136(74.3 \%)$ controls had parity of $2+$ and $13(14.1 \%)$ cases and 25 (13.7\%) controls had an abortion in their lifetime. Sixteen (17.4\%) cases and 27 (14.8\%) controls ever had a stillbirth. Nearly two-thirds (64.1\%) of cases and the majority controls 170 (92.9\%) had ANC visits during

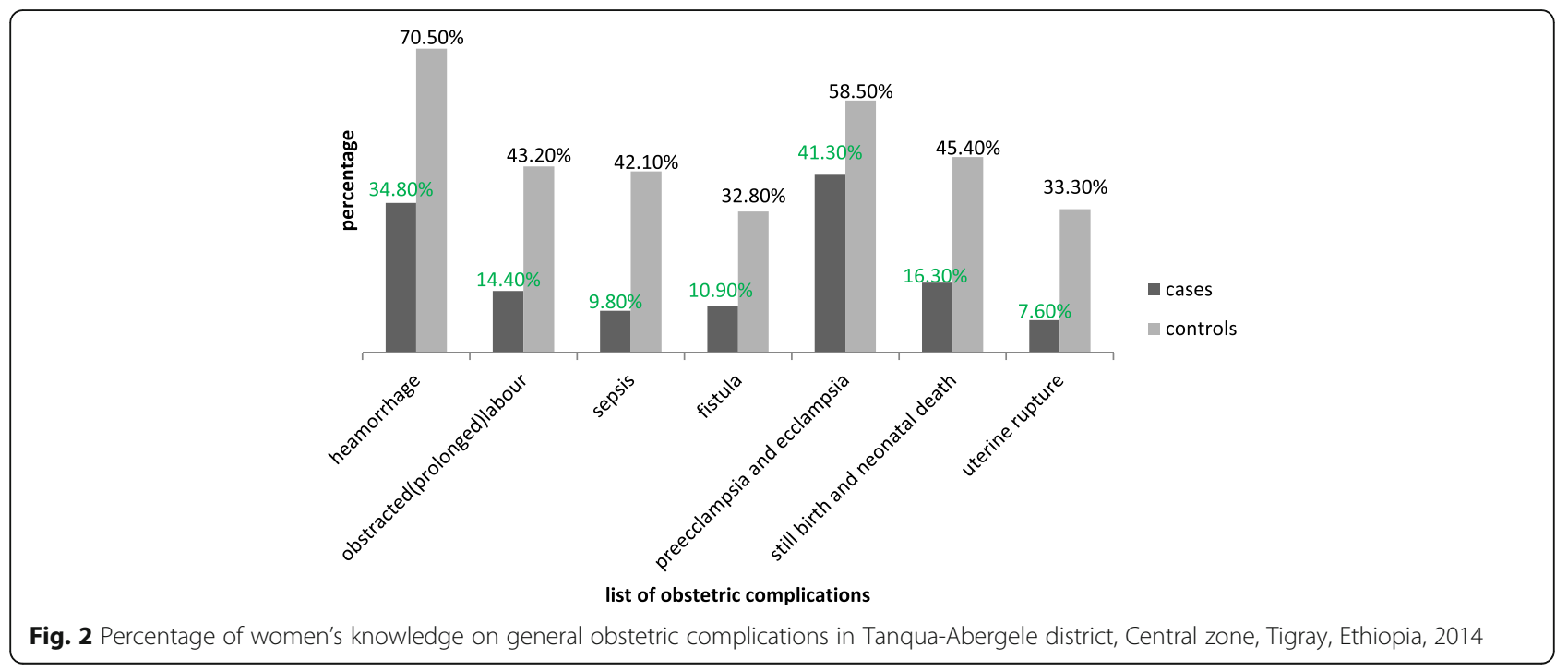


their last pregnancy. Out of these, $32(54.2 \%)$ and of 90(52.9\%) started ANC follow up at 12-24 weeks of gestation, Sixty-seven (72.8\%) cases had "poor knowledge" of danger signs during pregnancy, but 108 (59\%) controls had "good knowledge" of danger signs. There was a significant difference between cases and controls in terms of parity, a number of ANC visits, knowledge of danger signs during pregnancy and knowledge of obstetric complications (Table 2).

Most commonly mentioned danger signs during pregnancy by cases were vaginal bleeding (26.1\%), severe headache $(26.1 \%)$ and severe abdominal pain $(22.8 \%)$. Controls cited a severe headache $(46.6 \%)$, vaginal bleeding $(42.1 \%)$ and severe abdominal pain $(26.8 \%)$ as danger signs (Fig. 1). Regarding knowledge of obstetric complications, the three most common complications revealed by cases and controls were hemorrhage $(34.8 \%$ and $70.5 \%)$, preeclampsia and eclampsia (41.3\% and 58.5\%), and stillbirth and neonatal death (16.3\% and $45.4 \%)$, respectively (Fig. 2).

\section{Healthcare infrastructure and transportation}

Median times to travel to the nearest health facility (health center) for cases and controls were 90 (IQR \pm 90 ) and $60(\mathrm{IQR} \pm 100)$ minutes, respectively. Concerning mode of transport, $48(45.2 \%)$ cases and $74(40.4 \%)$ of controls cited walking. There was a significant difference between cases and controls in the availability of health centers, time to reach the nearest health institution, preference of ambulance service, and ever having received counseling about the place of delivery (Table 3).

\section{Factors associated with home delivery}

Adjusting for other variables, women who did not possess a radio or television had increased odds of home delivery compared to their counterparts (AOR: 7.24, 95\% CI: 2.7119.33). Similarly, women who did not have an ANC follow-up (AOR: 10.41, 95\% CI: 2.92-37.19) and those with1-3 ANC visits only (AOR: 4.75, 95\% CI: 1.69-13.31) had greater odds of delivering at home compared with women who had 4 or more ANC visits. The odds of home delivery was 8.75 times greater among women with "poor knowledge" of obstetric complications as compared to women who had "good knowledge"(AOR: 8.75, 95\% CI: 2.32-32.92). Time to reach health institution on foot was strongly associated with home delivery. The odds of home delivery was5.15 times higher among women living more than two hours walking distance to the nearest health center compared to those within one hour of the nearest center (AOR: 5.15, 95\% CI: 1.28-20.70) (Table 4).

\section{Discussion}

In Ethiopia, $88.3 \%$ of births are delivered at home [15]. This high rate of home delivery is explained by
Table 3 Health care (Programme) related characteristics of study participants in Tanqua-Abergele District, Tigray, north Ethiopia, 2014

\begin{tabular}{|c|c|c|c|}
\hline Variables & $\begin{array}{l}\text { Cases } \\
\text { No (\%) }\end{array}$ & $\begin{array}{l}\text { Controls } \\
\text { No (\%) }\end{array}$ & $\begin{array}{l}\text { Chi-square, } \\
\mathrm{df}, p \text {-value }\end{array}$ \\
\hline \multicolumn{4}{|l|}{$\begin{array}{l}\text { Presence of health facility } \\
\text { in their kebelle }\end{array}$} \\
\hline No & $40(43.5)$ & $46(25.1)$ & $x^{2}=9.583, d f=1$ \\
\hline yes & $52(56.5)$ & 137(74.9) & $P$-value $=0.002$ \\
\hline \multicolumn{4}{|l|}{ Road accessibility to the $\mathrm{HC}$} \\
\hline no & 33(35.9) & $31(16.9)$ & $x 2=12.286, d f=1$ \\
\hline yes & $59(64.1)$ & 152(83.1) & $P$-value $=0.000$ \\
\hline \multicolumn{4}{|l|}{ Mode of transportation } \\
\hline Ambulance & $\begin{array}{l}45 \\
(45.7)\end{array}$ & 103(56.3) & $x^{2}=3.47$ \\
\hline Public transport & $2(2.2)$ & $6(3.3)$ & $d f=2$ \\
\hline On foot & $48(45.2)$ & $74(40.4)$ & $P$-value $=0.176$ \\
\hline \multicolumn{4}{|l|}{$\begin{array}{l}\text { Time to reach the } \mathrm{HC} \text { in } \\
\text { minutes }\end{array}$} \\
\hline$<60 \min$ & $27(29.3)$ & $111(60.7)$ & $x 2=24.738$ \\
\hline $60-120 \mathrm{~min}$ & $39(42.4)$ & $48(26.2)$ & $d f=2$ \\
\hline$>120 \min$ & $26(28.3)$ & 24(13.1) & $P$-value $=0.00$ \\
\hline \multicolumn{4}{|l|}{$\begin{array}{l}\text { Preferred getting } \\
\text { ambulance service }\end{array}$} \\
\hline no & $22(23.9)$ & 23(12.6) & $x^{2}=5.757, d f=2$ \\
\hline yes & $70(76.1)$ & 160(87.4) & $P$-value $=0.016$ \\
\hline \multicolumn{4}{|l|}{$\begin{array}{l}\text { Ever gotten counselling } \\
\text { about place of delivery }\end{array}$} \\
\hline No & 10(10.9) & $2(1.1)$ & $x^{2}=14.022, \mathrm{df}=1$ \\
\hline yes & $82(89.1)$ & 181(98.9) & $P$-value $=0.000$ \\
\hline \multicolumn{4}{|l|}{ Counselling provider $(n=263)$} \\
\hline health workers & $34(41.5)$ & $81(44.8)$ & $x 2=18.252$ \\
\hline $\begin{array}{l}\text { women development } \\
\text { army(WDA) }\end{array}$ & $6(7.3)$ & $28(15.5)$ & $d f=4$ \\
\hline $\begin{array}{l}\text { Family(husband, Mother, } \\
\text { father) }\end{array}$ & 18(22.0) & $11(6.1)$ & $P$-value $=0.001$ \\
\hline health worker and WDA & 14(17.1) & 25(13.8) & \\
\hline $\begin{array}{l}\text { health worker WDA and } \\
\text { family }\end{array}$ & $10(12.2)$ & 36(19.9) & \\
\hline
\end{tabular}

several factors related to education, wealth, and access to healthcare. In our study, women who didn't possess a radio or television, those who didn't attend ANC at all or had few visits, those with poor knowledge of obstetric complications, and those living far away from health institutions all had higher odds of home delivery.

Our finding showing increased odds of institutional delivery among women owning a radio or television is consistent with other studies in Ethiopia, Ghana, Indonesia, and India [15-19]. Radio and television ownership likely increases women's knowledge about pregnancy and labor, 
Table 4 Predictors of Home Delivery in Tanqua-Abergele District, Tigray, north Ethiopia, 2014

\begin{tabular}{|c|c|c|c|c|}
\hline Variables & Cases No (\%) & Controls No (\%) & Crude OR (95\% Cl) & Adjusted OR (95\% Cl) \\
\hline \multicolumn{5}{|l|}{ Residence } \\
\hline Rural & $90(97.8)$ & $138(75.4)$ & $14.67(3.47-61.99)$ & 2.83(0.42-19.17) \\
\hline Semi rural & $2(2.2)$ & $45(24.6)$ & 1 & 1 \\
\hline \multicolumn{5}{|l|}{ Have a radio or TV } \\
\hline No & $69(75)$ & $83(45.4)$ & $3.61(2.08-6.29)$ & $7.24(2.71-19.33)^{a}$ \\
\hline Yes & $23(25)$ & $100(54.6)$ & 1 & 1 \\
\hline \multicolumn{5}{|l|}{ Have a radio or TV } \\
\hline No visit at all & 33(35.9) & $13(7.1)$ & $20.13(8.61-47.04)$ & $10.41(2.92-37.19)^{a}$ \\
\hline $1-3$ visits & $45(48.9)$ & $59(32.2)$ & $6.05(3.07-11.91)$ & $4.75(1.69-13.31)^{\mathrm{a}}$ \\
\hline Four and above & $14(15.2)$ & $111(60.7)$ & 1 & 1 \\
\hline \multicolumn{5}{|c|}{$\begin{array}{l}\text { Knowledge on danger } \\
\text { signs of pregnancy }\end{array}$} \\
\hline Poor & $67(72.8)$ & $75(41)$ & $3.86(2.24-6.66)$ & $1.75(0.65-4.75)$ \\
\hline Good & $25(27.2)$ & 108(59) & 1 & 1 \\
\hline \multicolumn{5}{|c|}{$\begin{array}{l}\text { Knowledge of obstetric } \\
\text { complication }\end{array}$} \\
\hline Poor & $82(89.1)$ & $99(54.1)$ & 7.95 (3.03-20.90) & $8.75(2.32-32.92)^{a}$ \\
\hline Moderate & $5(5.4)$ & $36(19.7)$ & $1.33(0.36-4.96)$ & 1.97(0.33-11.83) \\
\hline Good & $5(5.4)$ & $48(26.2)$ & 1 & 1 \\
\hline \multicolumn{5}{|c|}{$\begin{array}{l}\text { Time to reach the } \mathrm{HC} \\
\text { in minutes }\end{array}$} \\
\hline$<60 \min$ & $27(29.3)$ & $111(60.7)$ & 1 & 1 \\
\hline $60-120 \mathrm{~min}$ & $39(42.4)$ & $48(26.2)$ & $3.34(1.84-6.06)$ & $1.46(0.52-4.14)$ \\
\hline$>120 \mathrm{~min}$ & $26(28.3)$ & $24(13.1)$ & $4.45(2.22-8.94)$ & $5.15(1.28-20.70)^{a}$ \\
\hline \multicolumn{5}{|c|}{$\begin{array}{l}\text { Presence of health facility } \\
\text { in the kebele }\end{array}$} \\
\hline No & $40(43.5)$ & $46(25.1)$ & $2.29(1.35-3.89)$ & $0.60(0.18-1.95)$ \\
\hline Yes & $52(56.5)$ & 137(74.9) & 1 & 1 \\
\hline \multicolumn{5}{|c|}{ Road accessibility to the $\mathrm{HC}$} \\
\hline No & 33(35.9) & $31(16.9)$ & $2.74(1.54-4.87)$ & $0.99(0.35-2.83)$ \\
\hline Yes & $59(64.1)$ & $152(83.1)$ & 1 & 1 \\
\hline
\end{tabular}

${ }^{a}$ Significantly associated at $P<0.05$

including danger signs and complications, and perhaps contributes to advance planning.

$\mathrm{ANC}$ is the most favorable contact point for mothers to get more information about the risks and problems they may encounter during delivery. The World Health Organization (WHO) recommends that women without complications should have at least four antenatal visits, the first of which should take place during the first trimester [15]. Our study revealed a strong association between fewer ANC visits and home delivery. Studies from Kathmandu, Nepal, and Malawi showed a strong connection between no/fewer than four ANC visits and home delivery $[9,20]$. Studies in Ghana's well as North Showa, Dabat, East Wollega, and Sekela District and Munisa Districts in Ethiopia showed that women who had more prenatal visits were more likely to deliver at the health institutions [16, 17, 19, 21-23] Failing to capitalize on ANC visits could be significant missed opportunity in the FMoH's efforts to reduce maternal mortality and morbidity.

Knowledge of obstetric complications was a strong predictor of home delivery in our study. The odds of home delivery were considerably higher among women with "poor knowledge "of obstetric complications. This result was consistent with a study in Bahir Dar [11]. Women with advanced knowledge of potential complications and danger signs are better able to choose preferred delivery location and attendant as well as arrange for transport to skilled care in case of emergency. Women are also able to arrange companions to travel with them. 
Our study showed a significant association between walking distance to the nearest health facility and home delivery. Women who lived greater than two hours walking time (distance) to the nearest health center as compared to those less than one hour walking time had considerably higher odds of delivering at home. This finding is in line with studies in Kathmandu, Nchelenge and Kaoma, Zambia, and East Wollega, Ethiopia [9, 10, $21,24,25]$. Women facing long walks may be particularly unwilling to consider travel to health centers during the critical hours preceding delivery. In a country where $85 \%$ of the population resides in rural areas with poor infrastructure and inaccessible roads, many Ethiopian women are simply too far from a facility to consider institutional delivery. Furthermore, where transportation is available, it may not be suitable for laboring women.

\section{Limitations}

Our study includes several limitations: The sampling frame was constrained to the records of mothers who gave birth at a health institution or home as contained in the Tanqua-Abergele family folder, which may not be comprehensive. Also, our study didn't collect information from the perspective of healthcare providers and husband to substantiate our findings.

\section{Conclusion}

Unable to meet the minimum requirement WHO of ANC service had a potential to give birth at home. Investing in infrastructure will contribute to improving maternal health. Having a different source of media (radio or television) could have a role in increasing the institutional delivery. Policy makers and other concerned bodies should give due attention to the fulfillment of infrastructure and educate women on the importance of institutional delivery.

\section{Abbreviations}

ANC: Antenatal care; AOR: Adjusted odd ratio; Cl: Confidence interval; IEOS: Integrated emergency obstetric and surgery; SPSS: Statistical package for social science; SSA: Sub-Sharan Africa; WHO: World Health Organization

\section{Acknowledgements}

We would like to thank Mekelle University, College of Health Sciences for funding this research. Our gratitude goes to supervisors, data collectors, study respondents and Tigray Regional Health Bureau, and Tanqua-Abergele District Health Office that facilitate the study. Finally, we would like to thank for Dr.Gelila Goba for providing us professional support in editing the language of the manuscript.

\section{Funding}

The research was supported by a grant from Mekelle University, College of Health Sciences. The granting agency did not have a role in the design; collection, analysis, and interpretation of data or; in writing the manuscript.

\section{Authors' contributions}

RT: MA: GY: AA: KK: had taken a principal role in the conception of ideas, developing methodologies, data collection, analyses and write up of the article. All authors read and approved the final manuscript.

\section{Competing interests}

The authors declare that they have no any competing interests.

\section{Consent for publication}

Not applicable

\section{Ethics approval and consent to participate}

Ethical approval was provided by the Mekelle University College of Health Sciences, Health Research Ethics Review Committee (reference ECR 0388/ 2014) on February 18, and 2014. Letter of permission to undertake the study was also obtained fromTanqua-Abergele District Health office with a reference number WTA/9242/12/16 on the date of 18/03/2016. All participants were informed about the purpose, advantage, and disadvantage of the study, anonymity and the right to refuse participation at any stage of the interview. Confidentiality of respondents was assured and written informed consent was obtained prior to each interview.

\section{Publisher's Note}

Springer Nature remains neutral with regard to jurisdictional claims in published maps and institutional affiliations.

\section{Author details}

${ }^{1}$ Areaya Kahsu Health Science college, Department of Midwifery, Axum, Tigray, Ethiopia. ${ }^{2}$ Mekelle university, College of health science, School of public health, Mekelle, Tigray, Ethiopia. ${ }^{3}$ Mekelle university, College of Health Science, Department of Nursing, Mekelle, Tigray, Ethiopia. ${ }^{4}$ Millennium Health Science college, Department of Nursing, Mekelle, Tigray, Ethiopia.

Received: 20 October 2015 Accepted: 2 March 2017

Published online: 04 April 2017

\section{References}

1. WHO, UNICEF, UNFPA and the World Bank. Trends in Maternal Mortality 1990 to 2010. Estimates Developed by WHO, UNICEF, UNFPA and the World Bank. Geneva: World Health Organization; 2012.

2. Central Statistical Agency [Ethiopia] and ICF International. Ethiopia Demographic and Health Survey 2014. Addis Ababa and Calverton: Central Statistical Agency and ICF International; 2014.

3. Hill K, Thomas K, Abou Zahr C, Say L, Inoue M, Suzuki E, Craig H. Estimates of maternal mortality worldwide between 1990 and 2005. Lancet. 2007;370:1311-9.

4. TRHB. Tigray Regional Health Bureau 2006 EFY Annual Profile. Mekelle: Federal Democratic Republic of Ethiopian Minster of Health; 2006.

5. WHO. Core health indicators. Geneva: World Health Organization Statistical Information System; 2007.

6. Ransom E, Yinger N. Making motherhood safer; overcoming obstacles on the pathway to care. USA: Population Reference Bureau; 2002.

7. WHO, UNICEF, UNPF. Maternal mortality in 2000. Geneva: Estimates developed by WHO-UNICEF and UNFPA WHO; 2004.

8. Tasneem F, Saira A, Shahid M. Psychosocial determinants of preferring home births. Biomedica. 2008;24(6):85-8.

9. Wagle RR, Sabroe S, Nielsen BB. Socioeconomic and physical distance to the maternity hospital as predictors for place of delivery: an observation study from Nepal. BMC Pregnancy Childbirth. 2004;4(1):8. available at http://www. ncbi.nlm.nih.gov/entrez/query.fcgi?cmd = Retrieve\&db = PubMed\&dopt = Citation\&list_uids $=15154970$

10. Mwewa D, Michelo C. Factors associated with home deliveries in a low income rural settingobservations from Nchelenge district, Zambia. Medical Journal of Zambia. 2010:37(4).

11. Abebe, et al. Factors associated with home delivery in Bahirdar, Ethiopia: A case-control study. BMC Res Notes. 2012;5:653.

12. Endalamaw M, Hawult T. The Level of Awareness on Danger Signs of Pregnancy and Associated Factors among ANC Attendant Pregnant Women in Debark Town, North West Ethiopia. Translational Medicine and Biotechnology. 2014:2(5). 
13. Messay H, Abebe G, Fisshaye A. Knowledge About Obstetric Danger Signs Among Pregnant Women In AletaWondo District, Sidama Zone, Southern Ethiopia. Ethiop J Health Sci. 2010;20:1.

14. Central Statistical Agency (Ethiopia) and ORC Macro. Ethiopia Demographic and Health Survey 2014. Addis Ababa and Calverton, MD: Central Statistical Agency and ORC Macro. 2014.

15. Yebyo H, Alemayehu M, Kahsay A. Why Do Women Deliver at Home? Multilevel Modeling of Ethiopian National Demographic and Health Survey Data. PLoS One. 2015;10(4):e0124718. doi:10.1371/journal.pone.0124718.

16. Nketiah-Amponsah E, Sagoe-Moses I. Expectant Mothers and the Demand for Institutional Delivery: Do Household Income and Access to Health Information Matter. 2009

17. Geberehiwot F. Assessment of Factors for Safe Delivery Service Utilization among Women of Childbearing Age in Ephratanagidim District, North Shoa Zone Amhara Regional State, Ethiopia, MSc thesis Addis Ababa University. 2009.

18. Mesfin N, Damen HM, Getnet M. Assessment of Safe Delivery Service Utilization among Women of Childbearing Age in North Gondar Zone, North West Ethiopia. Ethiop J Health Dev. 2004;18(3):146-52.

19. Mengesha, et al. Determinants of skilled attendance for delivery in Northwest Ethiopia: a community based nested case-control study. BMC Public Health. 2013;13:130. Available at http://www.biomedcentral.com/ $1471-2458 / 13 / 130$

20. Palamuleni M. Determinants of non-institutional deliveries in Malawi. Malawi Med J. 2011;23(4):104-8. Available at http://www.ncbin.nlm.nih.gov/entrez/ query.fcgicmd $=$ Retrieve\&db $=$ PubMed\&dopt $=$ Citation\&list_uids = 23451561.

21. Feyissa TR, Genemo GA. Determinants of Institutional Delivery among Childbearing Age Women in Western Ethiopia, 2013: Unmatched Case Control Study. PLoS One. 2014;9(5):e97194. doi:10.1371/journal.pone. 0097194.

22. Teferra AS, Alemu FM, Woldeyohannes SM. Institutional delivery service utilisation and associated factors among mothers who gave birth in the last 12 months in Sekela District, North West of Ethiopia: a community-based cross-sectional study. BMC Pregnancy and Childbirth 2012 12:74: doi: 10. 1186/1471-2393-12-74

23. Amano, et al. Institutional delivery service utilization in MunisaDistrict, South East Ethiopia: a community based cross-sectional study. BMC Pregnancy Childbirth. 2012;12:105. Available at http://www.biomedcentral.com/14712393/12/105.

24. Simbuwa IL, Amukena N. Factors associated with home delivery in Kaoma Central Constituency of Kaoma District University of Zambia. 2012.

25. Gabrysch S, Cousens S, Cox J, Campbell OMR. The Influence of Distance and Level of Care on Delivery Place in Rural Zambia: A Study of Linked National Data in a Geographic Information System. PLoS Med. 2011;8(1):e1000394. doi:10.1371/journal.pmed.1000394.

\section{Submit your next manuscript to BioMed Central and we will help you at every step:}

- We accept pre-submission inquiries

- Our selector tool helps you to find the most relevant journal

- We provide round the clock customer support

- Convenient online submission

- Thorough peer review

- Inclusion in PubMed and all major indexing services

- Maximum visibility for your research

Submit your manuscript at www.biomedcentral.com/submit 